\title{
Dois Poemas Árabes Pré-Islâmicos
}

\author{
Mamede Mustafa Jarouche
}

Resumo: Este trabalho é uma tentativa preliminar de traduzir ao português as célebres mu 'allaqas pré-islâmicas de Imru' Alqays e 'Antara Bin Šaddād.

Palavras-chave: Poesia árabe; poesia pré-islâmica; tradução de poesia árabe; literatura árabe.

O período anterior ao surgimento do islã conheceu intensa atividade poética na Península Arábica. Essa produção, que somente foi recolhida por escrito no segundo século da Hégira, ficou conhecida como poesia do período jāhilī, isto é, do período da "ignorância", expressão cujo sentido decerto está relacionado, de uma parte, com o desconhecimento do islã propriamente dito, e, de outra, com alguns hábitos beduínos específicos que essa religião condenava.

Entre os poemas mais bem logrados do período, celebrizaram-se os conhecidos como mu 'allaqāt, vocábulo de sentido controverso que, literalmente e isolado, significa "penduradas" (ou suspensas). Em períodos mais tardios, certos historiados atribuíram tal denominação ao fato de que tais poesias teriam sido premiadas, registradas por escrito e penduradas na Ka'ba, templo religioso de Meca. Mais recentemente, tem-se defendido a hipótese de que a palavra mu'allaqa, na verdade, significa "comentada". Com efeito, o verbo do qual deriva, 'allaqa, "pendurar", quando seguido da preposição 'alà, "sobre", assume o significado de "comentar". Assim, portanto, seriam "comentadas" tais poesias por sua qualidade, que as tornava objeto de memorização e comentários de poetas, rapsodos e ouvintes em geral. Seu número varia, conforme os historiadores, entre sete e dez. 
Embora normalmente identificada, pela ignorância geral e genérica a respeito de assuntos árabes, com a controversa esfera de uma "oralidade" caótica que lhe subtrai toda e qualquer determinação, deve-se notar que tal poesia pertence mais ao âmbito do que pode ser, grosso modo, caracterizado como "pensamento letrado"; ou seja: seu modo de produção era "oral" simplesmente porque o suporte material - papel ou similares - inexistia ou era bastante escasso naquele meio. Porém, as regras que regiam a composição de tais poesias são de um rigor formal que dificilmente pode ser identificado com a "oralidade" tal como a pensam hoje - manifestação popular iletrada mas aceita com condescendência por letrados gentis e eventualmente engajados etc.

É de estrito dever ressalvar o fato de que a recolha de poesia pré-islâmica bastante ampla, e, conforme se disse, tardia - teve sua "autenticidade", diga-se assim, posta em dúvida por mais de um crítico contemporâneo; contudo, os critérios para tais restrições se pautavam, em geral, por critérios subjetivistas e autorais, logo românticos, anacrônicos e absolutamente inadequados para o período em questão.

Mas o escopo deste trabalho não é pôr em discussão tais critérios, nem realizar uma análise desses poemas, nem sequer apresentar uma descrição de seu sistema formal; o que se pretende, apenas e tão-somente, é apresentar uma tradução - preliminar - de dois desses célebres poemas, o primeiro de Imru' Alqays, considerado pelo próprio profeta Muhammad uma espécie de príncipe dos poetas pré-islâmicos, e o segundo de 'Antara Bin Šaddād Al'absī, que séculos mais tarde se tornaria personagem principal de uma extensa novela de cavalaria com seu nome. $\mathrm{O}$ texto utilizado como base foi o fixado por Sulaymān Al'ațțār, professor da Universidade do Cairo, em Šarh Almu'allaqāt Assab ' (Explicação das Sete Mu'allaqas), Cairo, 1982.

MU`AllaQA DO POETA IMRU’ AlQAYS (m. c. 540 D.C.)

01. "Alto! Choremos a memória de um amor e um acampamento

situado ao termo de sinuosas dunas, entre Dahūl e Hawmal, 02. e Tüdihh e Miqrät, cujos vestígios não foram varridos

pela urdidura dos ventos sul e norte:

03. vê-se ainda excremento de gazelas, em seus recantos 
e traçados, semelhando grãos de pimenta".

04. É como se, na madrugada em que partiram,

eu, em meio às acácias da aldeia, mastigasse coloquinto,

05. e meus amigos, em seus camelos, inertes

me dissessem: "não morras de angústia; paciência".

06. Minha cura, porém, é a lágrima transbordante.

"De que adianta chorar ante evanescentes ruínas?

07. Assim sofreste antes por Umm Alhuwayriț, ou ainda por sua vizinha Umm Arrabāb, em Ma'sal:

08. quando passavam, seu almíscar se tornava sopro do zéfiro com aroma de cravo".

09. Então minhas lágrimas desceram, abundantes, pelo peito escorrendo até molhar-me a cintura.

10. [Pensei:] "quantos dias faustosos gozaste com elas, sobretudo o dia de Dārat Juljul,

11. quando para as moças sacrifiquei meu camelo:

que assombro vê-las carregar-lhe as carnes,

12. pondo-se ao depois a atirar entre si os nacos

e a gordura, que parecia flocos de seda trançada;

13. o dia no qual adentrei a liteira de 'Unayza, que disse: "ai de ti, hás de me derrubar!";

14. eis o que ela alegava enquanto passava o cortejo:

"assustaste meu camelo, Imru' Alqays; desce, portanto!"

15. Eu disse: "avança e solta-lhe as rédeas,

mas não me impeças de colher teus frutos, iguais

16. aos de tanta mulher a quem, mesmo prenha ou lactante, fiz noturnas visitas,

fazendo-a esquecer o bebê protegido por amuletos:

17. quando chorava, ela dele cuidava só mexendo

metade do corpo, pois debaixo de mim a outra metade imóvel ficava."

18. [E outra,] um dia, sobre uma duna, dispensou-me asperamente,

e rompeu comigo num juramento sem volta.

19. "Ai, Fatinha, devagar com essa negaça:

se for para romper, seja, mas com gentileza;

20. estás assim iludida pensando que teu amor me mata, 
e tudo que ordenares meu coração fará;

21. se em minhas maneiras algo te aborrece, separa então tuas roupas das minhas: desnudos ficaremos.

22. Teus olhos só verteram lágrimas para atirares

tuas setas nos pedaços de um coração dilacerado.

23. Com quantas beldades mui ciosas em tendas inacessíveis

diverti-me em gozo não apressado,

24. e ludibriei vigias e familiares

cuidadosos, que em segredo me matariam,

25. quando as Plêiades no céu apareciam

como pedaços de um colar de intercaladas contas.

26. Cheguei, e ela, já desnuda para dormir, salvo a roupa íntima, me aguardava.

27. Ela disse: "por Deus que não tenho como te impedir, nem creio que esta atração desapareça".

28. Saímos juntos, ela arrastando atrás de nós

a cauda de sua sedosa camisola pintada.

29. Quando cruzamos os limites da aldeia, e tranqüilos ficamos, num declive seguro, em rocha de arenito recostados,

30. tomei-a pelas têmporas, empolgando-lhe

a graciosa cintura e o grosso lugar do chocalho.

31. Elegante, clara a pele, sem gorduras, pescoço liso como superfície de espelho;

32. primícia de alvura mesclada de leve amarelo, regada por transparência de água intocada, 33. a face esconde ou só a furto exibe, com olhares de vaca selvagem com cria, 34. delicado colo, como se fora de gazela branca, quando se ergue, sem atavios, 35. e longa cabeleira negra ornando a espádua, densa como trançado cacho de palmeira, 36. as tiaras elevadas em seu cimo, em suas melenas se extravia o pente.

37. Gentil o talhe, apertado como trança, e pernas como tronco de frondosa palmeira. 
38. O pó do almíscar lhe cobre o leito, em que repousa ao meio-dia, leve a roupa, 39. estendendo os tênues e suaves dedos como se fossem larvas de Zabī ou palitos de dente da árvore 'ishāl. 40. Ela ilumina as sombras do entardecer qual fora lampião de noturno monge solitário.

41. São as iguais a ela que o prudente deseja com ardor, quando surgem entre roupas adultas e infantis.

42. A escuridão [ $d a$ velhice] faz o homem desdenhar a juventude, mas meu coração jamais se apartará da paixão por ti.

43. De quanto adversário tenaz [de meu amor] recusei

os imperdoáveis conselhos e as censuras!

44. Quanta noite qual onda marinha soltou seus véus sobre mim para afligir-me com vários pesares!

45. Eu disse à noite, quando a escuridão se dilatava, espreguiçando-se, seu traseiro se afastando de seu peito:

46. "Ó longa noite, vira logo

madrugada, ainda que a aurora não seja melhor!

47. Noite, noite cujas estrelas parecem

cordas de linho em sólida rocha.

48. De quanto odre do povo pus os cabos

em minhas costas, obediente e esforçado!

49. Quanto vale tal bojo de asno, inóspito, cortei, no qual uivavam lobos como um desterrado!

50. Eu disse ao lobo uivador: nosso caso

é o do desafortunado sem riqueza.

51. Ambos, mal conseguimos algo, perdemos;

quem obra como eu e tu, está desgraçado.

52. Cedo madrugo, os pássaros inda no ninho, e monto veloz corcel, perseguidor de feras, vigoroso,

53. que, indo e vindo, avançando e recuando, semelha uma rocha de cima arrastada pela torrente; 54. é baio, e sua crina resvala pelo dorso como desliza pela lisa rocha o granito da chuva; 55. nervoso e delgado, quando trota, 
impaciente, parece uma caldeira a ferver; 56. galopa mesmo quando outros, fatigados, levantam poeira no duro solo pisado; 57. faz cair de seu lombo ao jovem ligeiro, e até ao forte corpulento faz perder as roupas; 58. impetuoso como pedra por moleques girada nas mãos e a uma corda amarrada;

59. de antílope são seus flancos, e de avestruz as patas, de lobo as passadas e de raposa a corrida; 60. espadaúdo, se o olhas por trás cobre todo o espaço com sua vasta cauda, quase arrastada ao chão, reta; 61. e seu dorso parece, quando avança, mó de noiva ou de coloquinto;

62. e é como se já o sangue das primeiras presas, em seu peito, fosse tinta de hena em cãs penteadas.

63. Avistamos caças cujas fêmeas pareciam donzelas de Duwār com comprida túnica, 64. que se dispersaram como contas de ônix intercaladas em pescoço de donzela de nobre origem.

65. Mas [o corcel] me fez alcançar as mais ligeiras, deixando atrás, não dispersadas, as mais lentas; 66. veloz atacou então touros e vacas, e os alcançou, sem que suor o molhasse. 67. E os cozinheiros, em largo espaço, preparavam as postas de carne para o assado e para cozinhar. 68. Naquela tarde, o olho mal podia segui-lo mal se mirava a parte de cima, logo o olhar descia; 69. sua sela e rendas passaram a noite com ele, que, de pé, ficou diante de mim sem se afastar.

70. Pois é, camarada: não vês o relâmpago cujo brilho te mostro, semelhante ao de suas patas, entre densas nuvens?

71. É seu fulgor que resplandece ou serão lampiões de monge, de retorcidas mechas em óleo empapadas?

72. Voltei a meus companheiros: entre Dārij

e 'Uzayb, tudo puderam contemplar! 
73. A tempestade parecia estender-se à direita, na direção de Qāṭan, e à esquerda, na direção de Sitār e a seguir Yazbul

74. Mas a água passou a refluir para os lados de Kutayfa, precipitando-se, frontal, em troncos de grandes árvores,

75. e salpicando, de passagem, Alqanān, ali desalojando de suas casas os bichos;

76. em Timā' não restou tronco de palmeira nem construção que não fosse de pedra ou argamassa;

77. Tabīra parecia, no início da tempestade, um grande líder com túnica riscada;

78. o alto do desfiladeiro de Mujaymir amanheceu, com a torrente e a enchente, como o cabo de um fuso;

79. e lançou, na depressão do deserto, sua carga, semelhando chegada de mercador iemenita cheio de trouxas;

80. é como se os pássaros do vale, pela manhãzinha, bebessem generoso néctar apimentado,

81. ou as feras, afogadas na véspera, por toda sua extremidade, fossem raiz de cebola.

\section{MU'ALLAQA DO POETA 'ANTARA Bin ŠADDĀD (m. século VI d.C.)}

1. Os poetas deixaram algo por ser glosado?

Ou por acaso conheceste a casa após ter-te iludido?

2. Fala, ó casa de 'Abla em Aljiwā'!

Bom dia, ó casa de 'Abla, e esteja bem!

3. É o lar da donzela de suaves contornos, afável abraço e doce boca sorridente.

4. Foi ali que detive minha camela, semelhante a um castelo que atendesse às necessidades de um desesperado.

5. 'Abla mora em Aljiwā', e nossa gente em Alḥazn, e Assammān e Mutatallam.

6. Salve, ó ruínas de antigos tempos, desertas e desoladas depois que se foi Umm Alhaytam.

7. Em terra de $[\mathrm{meu}]$ inimigo vives, e é 
difícil para mim procurar-te, filha de Mahram;

8. Sem querer, enamorei-me dela enquanto matava sua gente:

por vida de teu pai que penso ser [tal paixão] um despropósito.

9. Mas tu, não duvides, ocupas em meu coração

o lugar da amada venerada.

10. Como visitar-te, se a tua família passa a primavera

em 'Unayzatayn e a minha em Algaylam?

11. Quando decidiste partir, foram

as camelas ajaezadas em noite escura,

12. E não me assustaram senão as fortes montarias

naquele lugar pastando os grãos de musgo,

13. entre elas quarenta e duas leiteiras

negras como longas plumas de negro corvo.

14. Mas cativo me tinha uma branca boca com lábios

de doce beijar, alimento delicioso:

15. como se o almíscar do perfumista em sua arca

precedesse a seus dentes, até ti, desde sua boca,

16. ou como bosque intacto, de plantas regadas

pela chuva de água limpa e impoluta,

17. favorecida por puras nuvens primaciais,

que deixam cada poça qual moeda,

18. fluindo e correndo, pois cada tarde

recolhe, sem cessar, a água;

19. e sozinhas ficam as moscas, com seu interminável

zumbido, como melopéia de bêbado,

20. cantando, esfregando as patas,

como maneta tentando bater pedra sobre pedra.

21. Ela anoitece e amanhece sobre acolchoado leito,

e eu passo a noite no lombo de um negro animal de rédeas,

22. meu leito é uma sela sobre um animal de fortes patas,

grandes ilhargas, robusto dorso.

23. Levar-me-ás até a casa dela, ó camela de Šadan,

de maldito leite obstruído?

24. Rápida, marchadeira noturna, bamboleante, devastando montículos de espinhosas plantas: 
25. segue mais tarde esmagando-os, tal avestruz sem orelhas, de juntas patas, 26. à qual se juntassem pequenas avestruzes como rebanhos iemenitas a mudo pastor bárbaro, 27. seguindo com a vista a crista de sua cabeça, como seguiriam uma liteira coberta com andor: 28. cabeça pequena, deixa seus ovos em Dū Al'ušayra, como um escravo sem orelhas portando comprida pele. 29. Minha camela bebeu água de Duhraḍayn e se tornou arisca: detesta os tanques inimigos 30. e parece evitar, com seu flanco direito, a voz do noturno cabeçudo:

31. é o lince que ataca, e se ela se protege, furiosa, ele arremete com as patas e a boca. 32. Ajoelha-se ao lado de Arradā' e parece lançar-se sobre talos quebrados e rangentes: 33. alcatrão ou betume coalhado, com que o fogo se aviva junto ao vaso, 34. Parece brotar atrás de suas orelhas, iracunda, segura, rápida como um macho robusto.

35. Se te cobres com véu diante de mim, sabe que sou hábil em vencer cavaleiros de couraça: 36. elogia-me pelo que de mim conheces, pois sou de amável trato se não me fazem injustiça; 37. mas se me fazem, acerba é minha resposta, amarga de sabor, como o gosto do coloquinto. 38. Bebi muito vinho, depois que o calor diminuiu, e paguei com reluzente moeda cunhada, 39. em ocre vaso, sulcado, emparelhado com brilhante garrafa, à esquerda, tapada. 40. Porém quando bebo consumo somente meu dinheiro; minha honra fica íntegra, sem mácula. 41. Passada a embriaguez, minha liberalidade não diminui: minha nobreza e qualidades continuam tais as conheces. 42. Quantas vezes a marido de beldade prostrei por terra, 
os membros silvando, qual sulco de lábio cortado:

43. minhas mãos se anteciparam com rápida estocada

e o sangue do atingido esguichava qual rubra tinta.

44. Por que não perguntas aos cavalos, ó fillha de Mālik,

o que ignoras e o que de mim desconheces?

45. Nunca deixo a sela de minha rápida montaria, vigorosa, muitas vezes ferida por campeões:

46. numas vezes se destaca ao fazer carga, e noutras

une-se ao tropel dos retesados arcos.

47. Que to diga quem me viu em tais batalhas:

como procuro a luta e desdenho os despojos.

48. A quantos campeões cujo enfrentamento faz temer guerreiros, não dados embora à fuga ou rendição,

49. minha mão assestou rápido golpe com reta lança de rijas pontas endereçada! 50. Atravesso com ela, rígida, toda roupa, pois nem o nobre é respeitado pela lança, 51. e deixei-os, pasto de feras que, tomando-os, mastigavam a formosura de seus dedos e seus pulsos.

52. De quantas cotas largas, espessas, rompi as junturas com a espada, deixando à mostra o corpo do guerreiro, 53. a mão preparada para jogar dados no inverno, abaixador, censurado, das bandeiras dos vendedores de vinho.

54. Ao ver-me avançar em sua direção, mostrou os dentes, não decerto sorrindo. 55. Avançado o dia, haveria de vê-lo como se sua cabeça e mãos estivessem tingidas de índigo;

56. tendo-o atingido e atravessado com um valente sabre de claro aço, cortante:

57. a um herói como uma árvore com vestido, calçado de couro de vaca, e não gêmeo! 58. Ovelha acessível a quem é lícita a mim continua proibida; oxalá não fosse! 60. Mandei-lhe minha escrava dizer: "vê, vigia tudo sobre ela, fica informada". 
61. Ela voltou dizendo: "vi o inimigo descuidado; a ovelha é acessível ao ferido por ela".

62. Ela se volta com pescoço de antílope, Formosa gazela de claro focinho.

63. Eu soube que alguém não me louva esta benesse, e ser ingrato é trair quem fez o bem.

64. Cumpri o conselho de meu tio, meio-dia, quando os lábios retesados mostram os dentes 65. em meio à guerra, de cujos rigores não se queixam heróis senão com gritaria; 66. eu, quando me usaram de barreira às lanças, não me acovardei, senão que estava estreito o lugar de avançar;

67. e quando vi chegar a toda a gente, inflamada, avancei, irreprochável.

68. Chamavam: “ó ‘Antara!”. As lanças pareciam cordas de poço no peito do negro cavalo.

69. Sem descanso, eu os atacava na covinha da garganta e do peito, até cobri-los de sangue;

70. [meu cavalo] esquivou-se do ataque de lanças ao peito, queixando-se com lágrimas e relinchos:

71. pudesse dialogar, protestaria; soubesse falar, me falaria.

72. Mas curou minha alma e the expulsou a debilidade o dizer dos ginetes: "avança, 'Antara!"

73. E os cavalos, taciturnos, irrompiam no chão mole, corcéis, todos eles puro-sangue.

74. Minha montaria é obediente; quero que me acompanhe o coração: movo-o com firme ordem.

75. Temi, porém, morrer sem que a guerra se volte contra os filhos de Damdam, 76. que insultaram minha honra, sem que eu os tivesse insultado, e juraram matar-me, quando eu não estava presente. 77. Que o façam não surpreende, pois tornei-lhes o pai pasto de feras e velhos abutres. 
Abstract: This work is a preliminary attempt to translate into Portuguese the most famous Imru' Alqays's and 'Antara Bin Šaddād's pre-Islamic mu'llaqas.

Keywords: Arabic poetry; pre-Islamic poetry; translation of Arabic poetry; Arabic Literature. 